\title{
Using Electrochemical Noise Technique to Evaluate the Corrosion Performance of a Reinforcement Magnesium Alloy
}

\author{
Mohamed Gobara \\ Egyptian Armed Force, Kobry Elkobba, Cairo, Egypt \\ E-mail address:m_gobara@yahoo.com
}

\begin{abstract}
AZ91D magnesium alloy was reinforced by titanium and boron carbides under an inert environment using in-situ reactive infiltration technique. The corrosion properties of the reinforced magnesium alloy were investigated using Electrochemical noise (EN) techniques in dilute Harrison solutions. The moving average removal (MAR) method was used as trend removal methods. The frequency of pitting events $\left(f_{\mathrm{n}}\right)$ and the average charge in each pitting events $(\mathrm{q})$ were calculated for each EN measurements. EN results shows that the addition of reinforcement improved the corrosion resistance of the magnesium alloy (R-Mg) and no signs of corrosion were observed during 10 days of immersion in the corrosive solution.
\end{abstract}

Keywords: EN; Composite materials; Corrosion; AZ91D alloy; Harrison solutions

\section{INTRODUCTION}

Magnesium is one of the most commonly used structural metals. It has a wide range of applications such as automotive, aerospace, guided missiles where the combination of strength and light weight are needed [1]. Moreover, it is around $65 \%$ the density of aluminium and $25 \%$ that of steel [2]. However, this wide range applications of magnesium alloys is limited due to their poor corrosion resistance, mainly in solution containing chloride ions.

Magnesium and its alloy are very active due to low corrosion potential (-1.5V vs SCE) leading to use it as a sacrificial electrode [3]. Furthermore, alloying elements and intermetallic particles within the magnesium alloy matrix act as cathodic sites that leads to increase corrosion rate of the magnesium matrix $[4,5]$.

Due to the high demand on magnesium alloys, researchers carry out series of studies related to the corrosion protection of magnesium alloys. Corrosion can be reduced by addition of proper alloying elements and/or reinforcement which also enhances the wear resistance [68]. The electrochemical noise is a suitable technique that applied without any external perturbation to the corroded system $[9,10]$. This advantage is not available compared with other electrochemical techniques.

The main objective of the current work is to study the corrosion behaviour of the fabricated composites using electrochemical noise technique EN to evaluate effect of the reinforcing phases with respect to that of the commercial AZ91D alloy. 


\section{EXPERIMENTAL}

\section{1. Material}

The reinforcement matrix ( $\mathrm{R}-\mathrm{Mg}$ ), was prepared by adding $\mathrm{TiC}, \mathrm{Ti}_{2} \mathrm{AlC}$ and $\mathrm{TiB}_{2}$ powder to molten AZ91D alloy using in-situ reactive infiltration technique. Experiments were carried out under inert environment of argon gas. The molten $\mathrm{Mg}$ alloy infiltrates a perform of 85 wt. $\%\left(3 \mathrm{Ti}_{\mathrm{p}}+\mathrm{B}_{4} \mathrm{C}_{\mathrm{p}}\right)+15$ wt. $\% \mathrm{MgH}_{2}$ at a processing temperature of $900{ }^{\circ} \mathrm{C}$ for $1.5 \mathrm{~h}$ holding time.

The samples were naturally cooled to room temperature. Commercial magnesium alloy AZ91D samples (obtained from Q-panels) were cleaned with deionised water followed by rinsing with ethanol and then left to dry for $30 \mathrm{~min}$ at $60{ }^{\circ} \mathrm{C}$. The sample was then cooled before corrosion and mechanical tests at room temperature. AZ91D has typically the following chemical composition (wt. \%)

\begin{tabular}{|c|c|c|c|c|c|c|c|c|}
\hline $\mathrm{Al}$ & $\mathrm{Zn}$ & $\mathrm{Mn}$ & $\mathrm{Si}$ & $\mathrm{Cu}$ & $\mathrm{Fe}$ & $\mathrm{Ni}$ & Others & $\mathrm{Mg}$ \\
\hline 8.8 & 0.68 & 0.30 & 0.01 & $<0.001$ & 0.004 & $<0.008$ & $<0.30$ & rest \\
\hline
\end{tabular}

Corrosion tests were carried out in a three-electrode type cell using the sample as the working electrode and a saturated calomel electrode (SCE) and a platinum electrode as reference and counter electrodes respectively.

Cyclic potentiodynamic polarization $(\mathrm{CP})$ scans were performed using an initial delay time at steady open-circuit potential (OCP) for $60 \mathrm{~min}$ to stabilize the surface. The polarization scan started from cathodic to anodic at a rate of $3 \mathrm{mV} / \mathrm{s}$.

Electrochemical potential and current noise were simultaneously measured in a freely corroding system employing two nominally identical working electrodes of the same area and a saturated calomel reference electrode. The area of each electrode exposed to the solution was about $1.0 \mathrm{~cm}^{2}$. The reference electrode was placed in the middle distance between the two working electrodes. The noise data were recorded for $1024 \mathrm{~s}$ at a sampling rate of $1 \mathrm{~s}$. The potential and current noise data collected in the time domain were transformed in the frequency domain through the fast Fourier transform (FFT) method. All data analysis was made using EAS410 Gamry software.

The microstructure and the phase analysis of the fabricated composite samples were investigated by scanning electron microscope (SEM) using Philips XL30.

\section{RESULTS AND DISCUSSION}

\section{1. Corrosion performance of the alloys}

Corrosion of multi-phase Mg alloy such as AZ91D in a corrosive solution is controlled by the relative amount and distribution of second phase particles with respect to magnesium matrix, (alpha magnesium) [11]. In general, these particles, such as $\mathrm{Mg}_{17} \mathrm{Al}_{12} \mathrm{M}$, have nobler corrosion potential than that of magnesium allowing them to work as cathodes with respect to alpha-Mg that would increase the corrosion rate of adjacent alpha-Mg matrix [12]. 


\section{1. 1. Polarisation Results}

The corrosion properties of AZ91 and as-synthesized R-Mg were investigated using a polarization technique (Tafel extrapolation technique) in dilute Harrison solution after one hour of immersion in the solution. As shown in Figure 1, the AZ91 sample has a corrosion current of about $4.51 \mathrm{~mA} / \mathrm{cm}^{2}$. The anodic branch of the AZ91 sample shows continuous active dissolution of the metal while the cathodic branch exhibits diffusion control (oxygen reduction reaction) corrosion.

In comparison, the corrosion current of the R-Mg sample is one order of magnitude lower than that of AZ91 sample being $0.38 \mathrm{~mA} / \mathrm{cm}^{2}$.

The polarization curve of $\mathrm{R}-\mathrm{Mg}$ sample, shown in Figure 1, exhibits a corrosion potential (1083 V mV vs. SCE) that is higher than that of AZ91 sample (1518V vs. SCE). Moreover, the slope of polarization of the anodic branch of $\mathrm{R}-\mathrm{Mg}$ sample shows different behavior than that of AZ91D and seems to be of passivition type. In addition the slop of anodic branch of R-Mg sample $(803 \mathrm{mV} / \mathrm{dec}$.) is much grater than that of AZ91D $(214 \mathrm{mV} / \mathrm{dec}$.) that implies $\mathrm{R}-\mathrm{Mg}$ has a much lower anodic dissolution, i.e. a higher resistance.

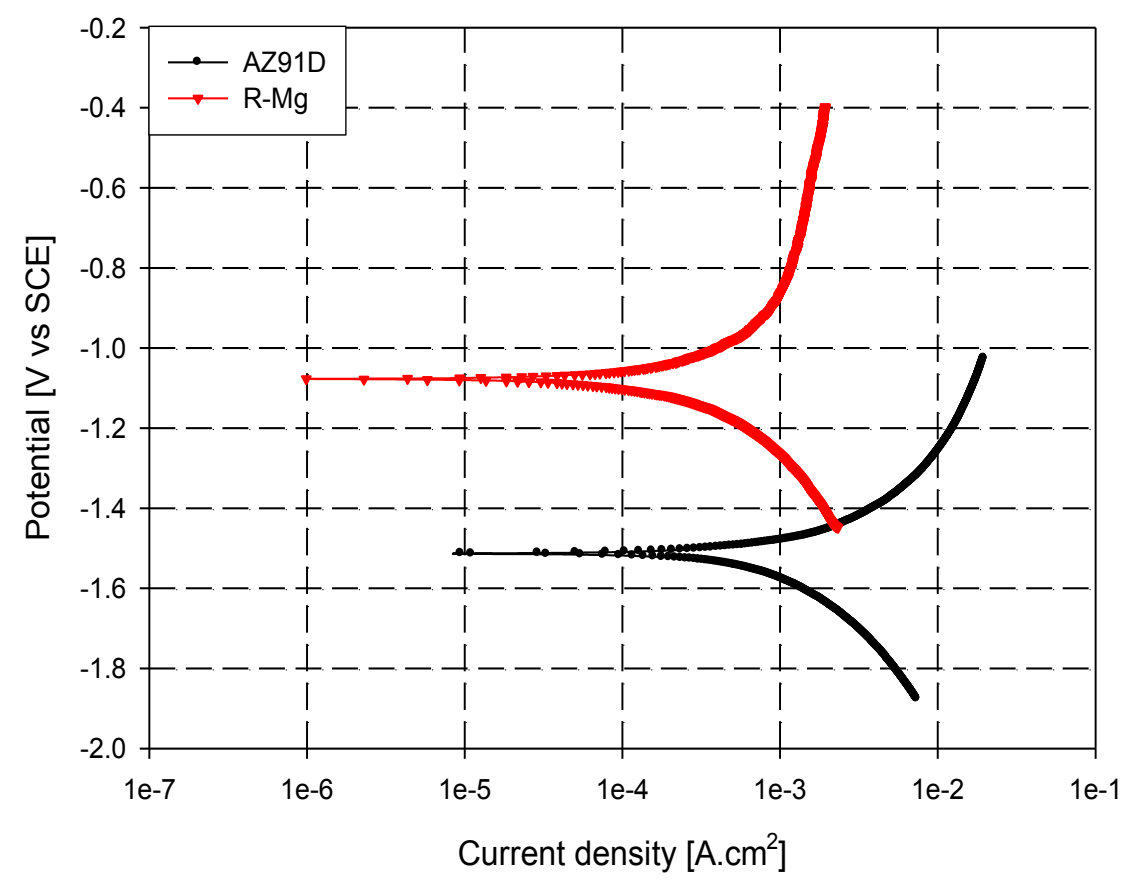

Figure 1. Polarization curves for AZ91 and R-Mg in dilute Harrison solution.

\section{1. 2 Electrochemical noise (EN) results}

In this part of investigation of the corrosion behavior of AZ91D and R-Mg alloys, the electrochemical current noise is recorded simultaneously and the data are analyzed in time domain, moreover, the corresponding frequency power spectral density (PSD) of current and potential plots of both alloys is studied. The noise resistance, $R_{\mathrm{n}}$, is determined in the time domain, as the ratio of the standard deviation of potential noise, $\sigma \mathrm{V}$, to that of current noise, $\sigma I$ according to the following equation: 


$$
\begin{aligned}
& R_{n}=\frac{\sigma V}{\sigma I} \\
& \text { where } \sigma V=\sqrt{\frac{\sum_{i=1}^{n}\left(V_{i}-m_{v}\right)^{2}}{n}}, \quad m_{v}=\frac{\sum_{i=1}^{n} V_{i}}{n} \\
& \sigma I=\sqrt{\frac{\sum_{i=1}^{n}\left(I_{i}-m_{i}\right)^{2}}{n}} \text { and } m_{i}=\frac{\sum_{i=1}^{n} I_{i}}{n}
\end{aligned}
$$

The DC trend was removed before the analysis of noise data in time domain. It was believed that DC trend can cause inaccuracy in the calculation of noise resistance from time domain analysis [13]. Among different trend removal methods, the moving average removal (MAR) method was used [14]. The main feature of MAR method is a d-trending by subtracting a local average from the noise data. Any data point in the series, $V_{\mathrm{i}}$, is a combination of the real noise component and the DC trend component:

$$
V_{i}=V_{i, n o i s e}+V_{i, D C}
$$

$V_{\mathrm{i} \text {, noise }}$ is the real noise and it required for noise resistance calculation where $V_{\mathrm{i}, \mathrm{DC}}$ is the DC trend component which has to be removed. The $V_{\mathrm{i}, \mathrm{DC}}$ values can be calculated according to the following equation

$$
V_{i, D C}=\frac{\sum_{i-p}^{i+p+1} V_{i}}{2 p+2}
$$

where $\mathrm{p}$ is an integer value that can be $3,10,16,32,64$ [15]. The DC trend in the voltage-time record can therefore be removed and the random fluctuation $V_{\mathrm{i} \text {,noise }}$ could be deduced as:

$$
V_{i, \text { noise }}=V_{i}-V_{i, D C}
$$

Similar procedure can be applied to get $I_{\mathrm{i} \text { noise. }}$.

Figure 2 shows the raw data of electrochemical current noise before and after removing of trend using MAR method with $\mathrm{p}=3$. Figure 3 shows the detrended electrochemical potential noise of both AZ91D and R-Mg samples. From Figures 2 and 3, it can be seen that the fluctuations of current and potential noises associated with AZ91D are more that that of R-Mg sample which indicates that the noise resistance of the AZ91D sample would be less than that of R-Mg one.

The corresponding noise resistances of both AZ91D and $\mathrm{R}-\mathrm{Mg}$ in dilute Harrison solution, taking different $p$ values as a MAR pretreatment, are listed in Table 1 . The table shows that AZ91D is more susceptible to corrosion than R-Mg. 

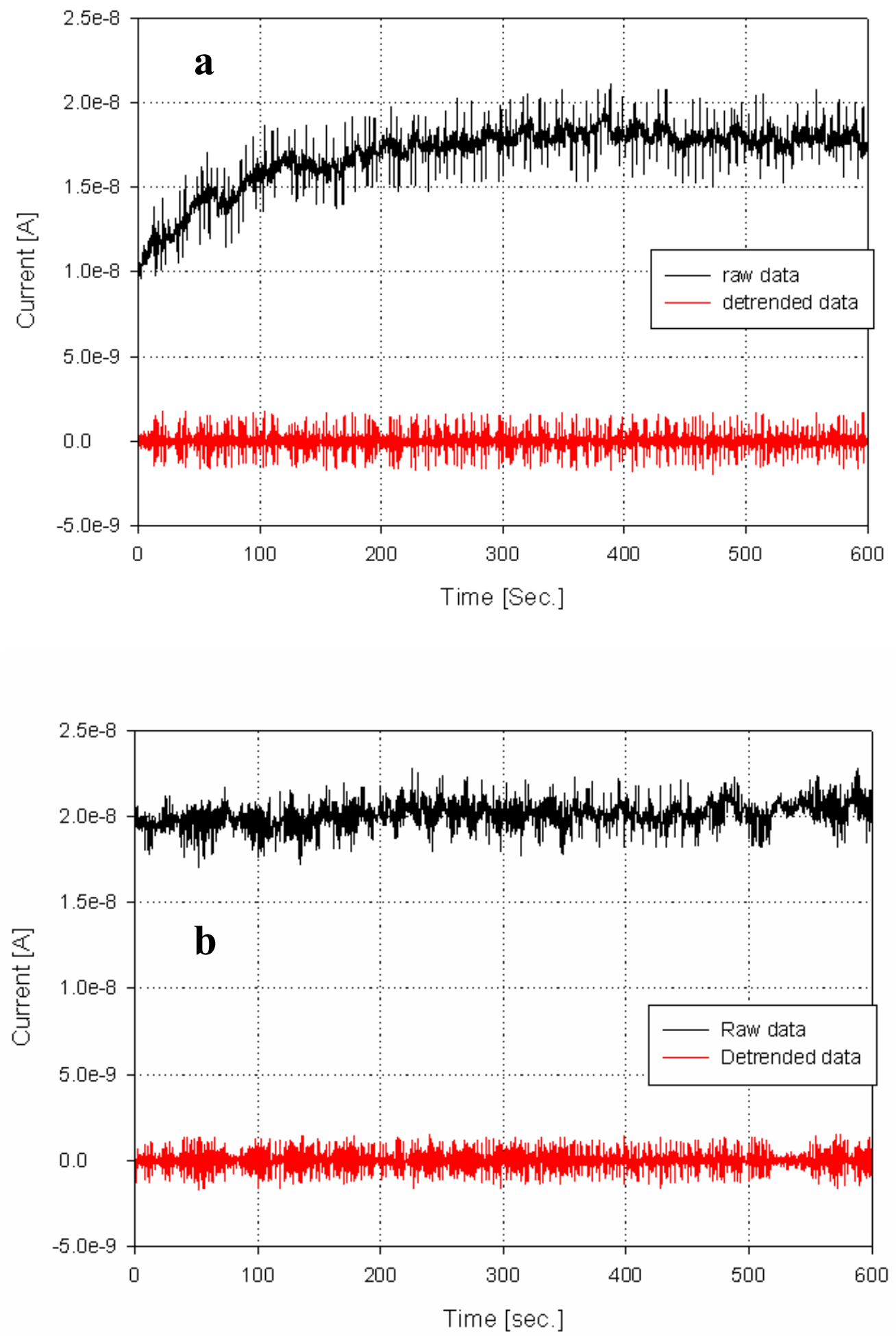

Figure 2. Time records of electrochemical current noise associated with (a) AZ91D and (b) R-Mg exposed to dilute Harrison solution before and after removal of DC trend (MAR parameter $p=3$ ). 


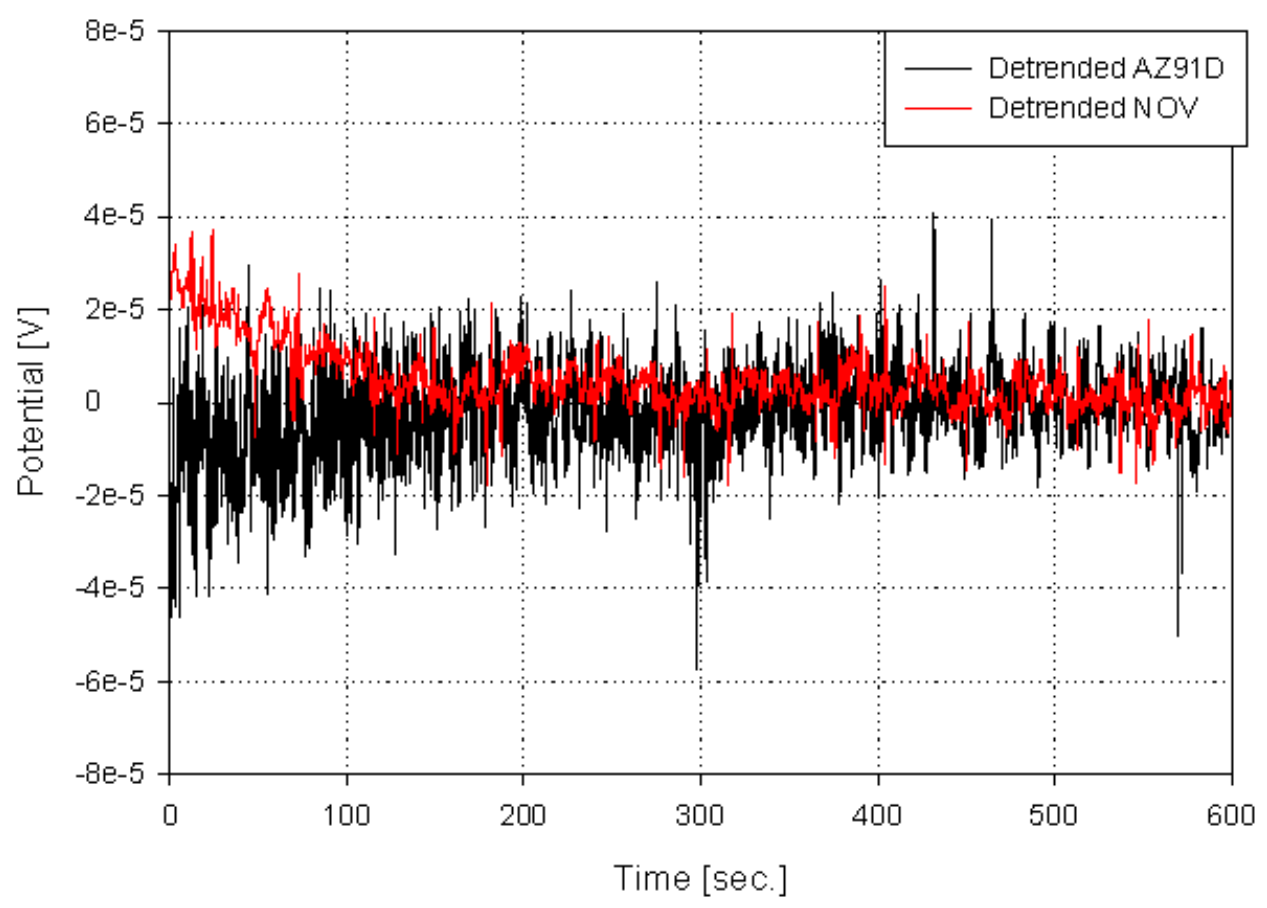

Figure 3. Time records of detrended electrochemical potential noise associated with both AZ91D and $\mathrm{R}-\mathrm{Mg}$ exposed to dilute Harrison solution (MAR parameter $\mathrm{p}=3$ ).

Table 1. The corresponding noise resistances of both AZ91D and R-Mg in dilute Harrison solution.

\begin{tabular}{|c|c|c|c|c|c|c|}
\hline \multirow{2}{*}{ Sample } & \multicolumn{7}{|c|}{$\mathrm{R}_{\mathrm{n}}\left[\mathrm{k} \Omega \mathrm{cm}^{2}\right]$} \\
\cline { 2 - 7 } & $\mathrm{P}=0$ & $\mathrm{P}=3$ & $\mathrm{P}=10$ & $\mathrm{P}=16$ & $\mathrm{P}=32$ & $\mathrm{P}=64$ \\
\hline AZ91D & 9.6 & 19 & 48 & 121 & 124 & 132 \\
\hline R-Mg & 190 & 41 & 130 & 197 & 201 & 217 \\
\hline
\end{tabular}

The electrochemical noise measurements was conducted at different immersion time and corresponding $R_{n}$, at $p=3$, are calculated as shown in Figure 4 . It can be seen that the noise resistance of $\mathrm{R}-\mathrm{Mg}$ sample sharply increases in the first 24 hour of immersion and then seems to be stable. However, the noise resistance of AZ91D slightly decreases with immersion time.

For more investigation, the shot noise analysis has been performed for electrochemical noise data to get the frequency of pitting events $\left(f_{\mathrm{n}}\right)$ and the average charge in each pitting events (q) [16]. Based on the frequency domain analysis of the electrochemical potential and current signals, $\Psi_{\mathrm{E}}$ and $\Psi_{\mathrm{I}}$ respectively, can be determined by calculating the mean PSD values of potential and current noise around at low frequency typically $0.01 \mathrm{~Hz}[15,17]$. 


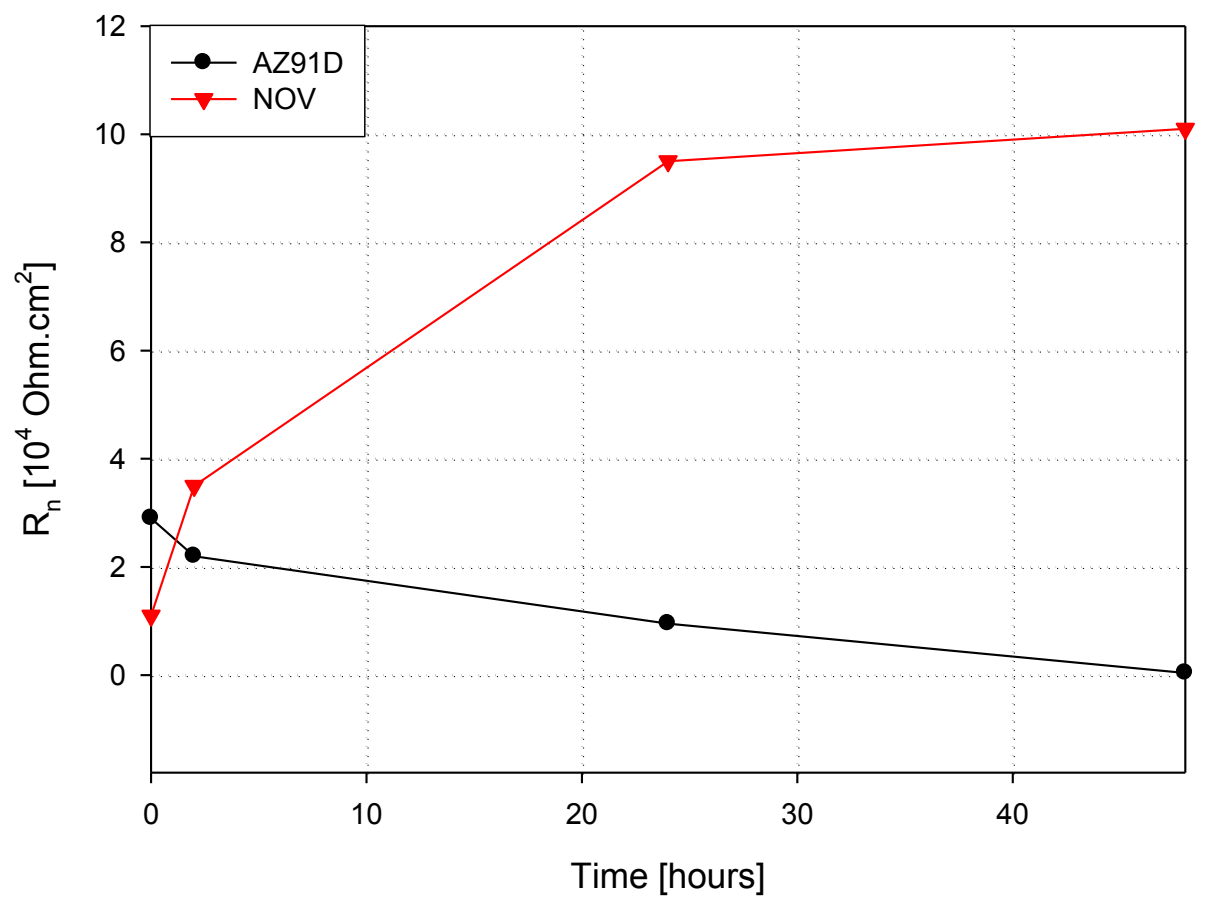

Figure 4. Change of noise resistance of both AZ91D and R-Mg with immersion time in dilute Harrison solution (MAR parameter $\mathrm{p}=3$ ).

$$
\begin{aligned}
& f_{n}=\frac{B^{2}}{\Psi_{E} A} \\
& q=\frac{\sqrt{\Psi_{E}} \sqrt{\Psi_{I}}}{B}
\end{aligned}
$$

where $\mathrm{A}$ is the area and B is the Stern-Geary constant which can be calculated from potentiodynamic measurements. Figure 5 shows the PSD current and potential of AZ91D and R-Mg samples. The shot noise (around $0.01 \mathrm{~Hz}$ ) analysis shows that the pitting characteristic frequency $\mathrm{n}$ of the AZ91D is approximately $58.8 \mathrm{~s}^{-1} \mathrm{~cm}^{-2}$ with the characteristic charge $\mathrm{q}$ of $220 \mathrm{nC}$ where the $f_{\mathrm{n}}$ and $\mathrm{q}$ of $\mathrm{R}-\mathrm{Mg}$ sample are $42.7 \mathrm{~s}^{-1} \mathrm{~cm}^{-2}$ and $83 \mathrm{nC}$ respectively. These results indicate that the AZ91D alloy is more susceptible to pitting corrosion than R-Mg sample when immersed in dilute Harrison solution.

From the above results of potentiodynamic polarization and EN, one can concluded that the corrosion resistance of reinforced matrix (R-Mg) is better than that of commercial AZ91D alloy. Morphology study is important in investigation of the mechanism of corrosion behaviour of both AZ91D and R-Mg sample. SEM analysis was conducted on the AZ91D sample after 10 days of immersion in dilute Harrison solution as shown in Figure 6. It is clear from the image that there was a layer that mechanically removed from a selected area to reveal the underlying surface. The arrows point out the remaining layer after removing the rest of layer to expose underlying surface. When AZ91D alloy immersed in an aqueous 
solution a magnesium hydroxide layer is formed on the metal surface. However, this layer can not protect the alloy in the presence of a corrosive medium containing $\mathrm{Cl}^{-}$, due to the porous nature of the hydroxide layer [18].
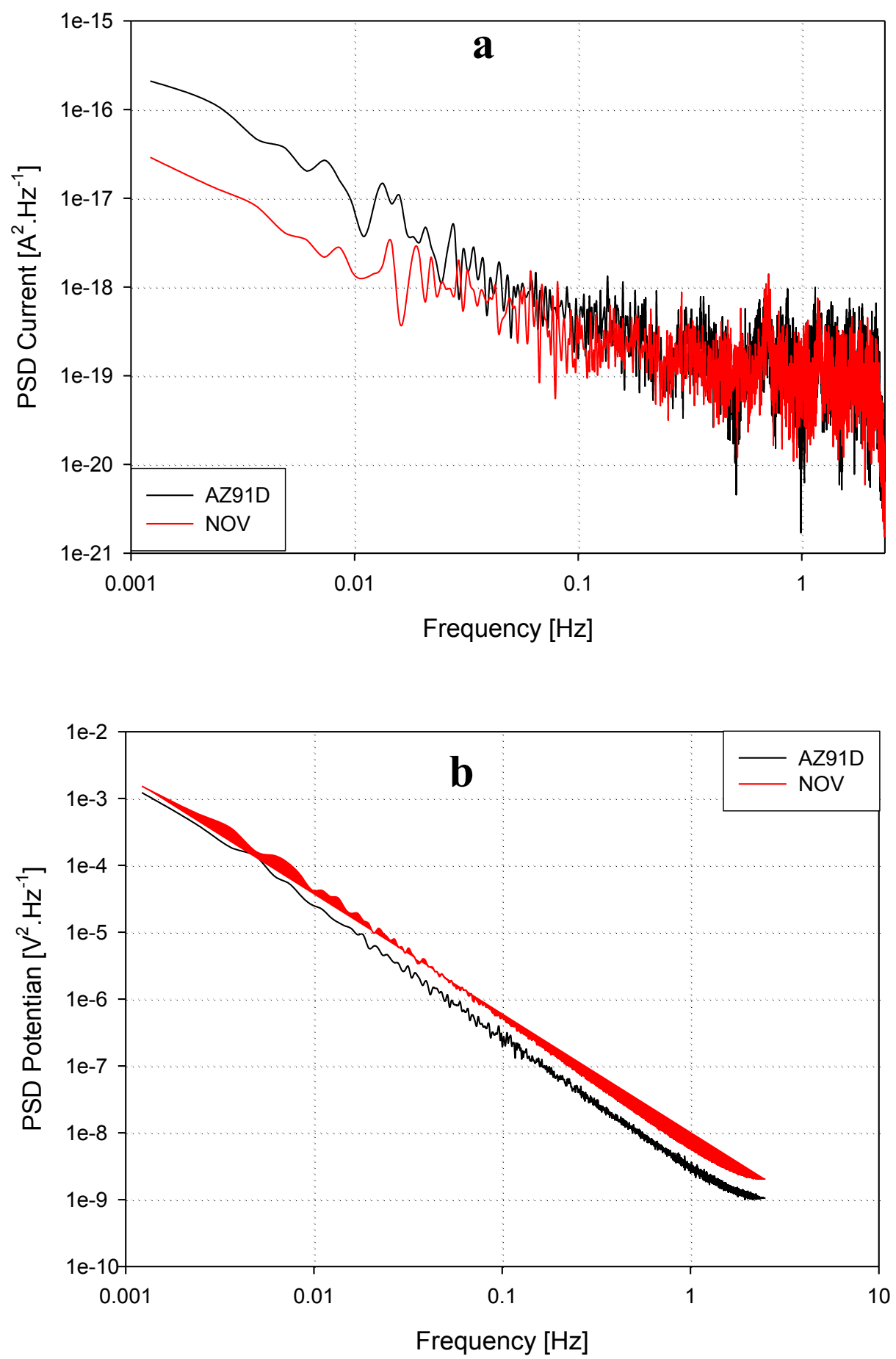

Figure 5. PSD (a) Current and (b) Potential plots associated with both AZ91D and R-Mg exposed to dilute Harrison solution 
The figure shows severe corrosion takes place over the entire metal surface with pitting being observed. AZ91D is a two-phase alloy where the second phase is not continuous which can not provide a passive barrier [12]. The magnesium matrix has a corrosion rate significantly greater than that of second phase in chloride containing corrosive solutions [11]. This pitting corrosion may relate to localised corrosion at the intermetallic particles, $\mathrm{Mg}_{17} \mathrm{Al}_{12} \mathrm{M}$, which form micro-galvanic cells with the surrounding alpha magnesium matrix leaving vacant sites on the surface [19].

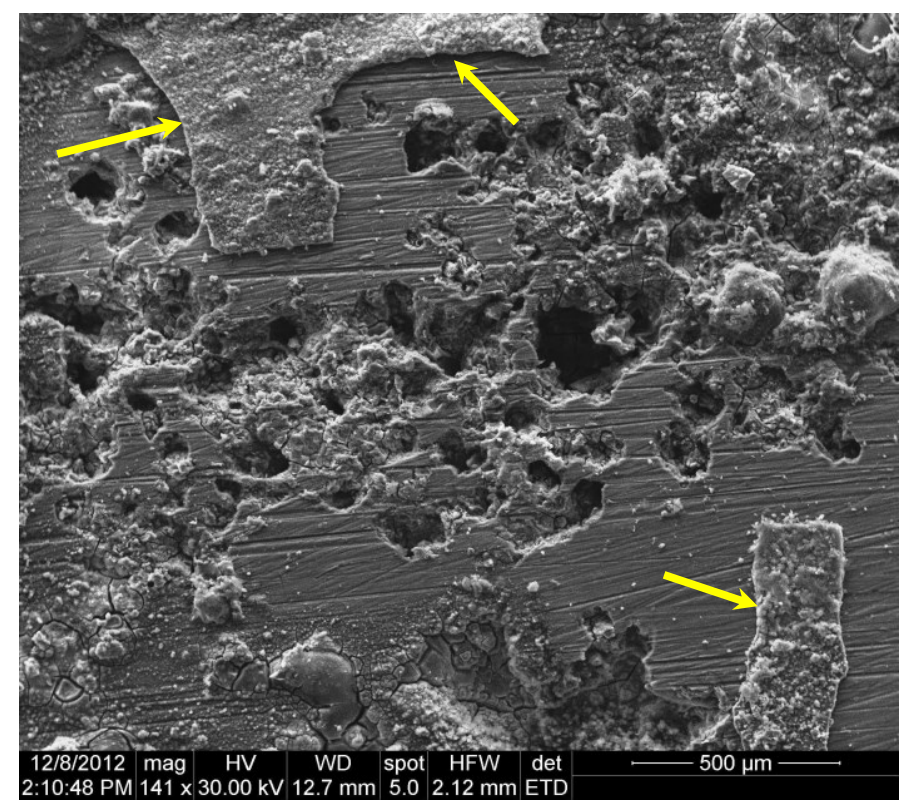

Figure 6. SEM image of bare AZ91 sample after immersion for 10 days in dilute Harrison solution.

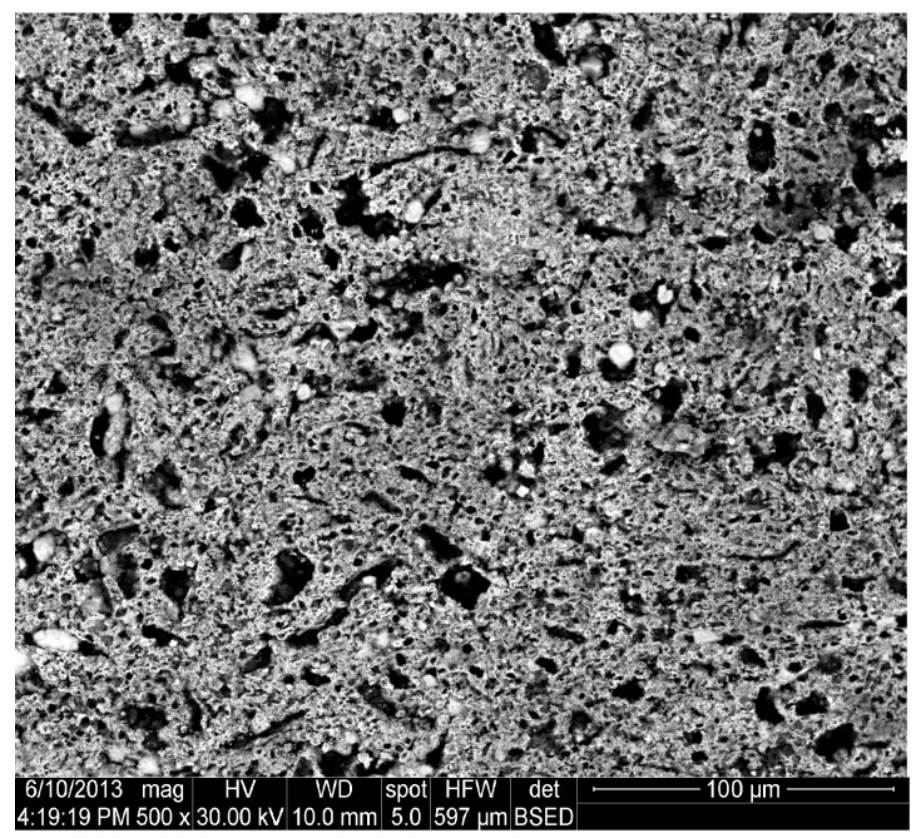

Figure 7. SEM image of bare R-Mg sample after immersion for 10 days in dilute Harrison solution. 
SEM image, Figure 7, shows that the surface of the sample after immersion in the corrosive solution for 10 days where it can see that the surface of the sample has network matrix that comprises some voids. Moreover, some white crystals are precipitated in these voids as shown from the SEM image which seem to be sodium chloride and some corrosion products due to interaction with the aqueous corrosive solution.

By comparing this SEM image with that of the original surface (Figure 8), it can be see that the matrix is continuous network and the magnesium fill the entire area of the network matrix. It would seem that the voids produced by dissolving of alpha magnesium from the metal surface. Alpha magnesium that appeared in the Mg map (Figure 8) does disappear in the SEM image of R-Mg sample after immersion in the corrosive solution (Figure 7). In addition EDAX mapping of the composite, figure 8, reveals uniform distribution of titanium, boron and aluminium network without any residual intermediate phases that would be reflected in the mechanical properties of $\mathrm{R}-\mathrm{Mg}$ sample.

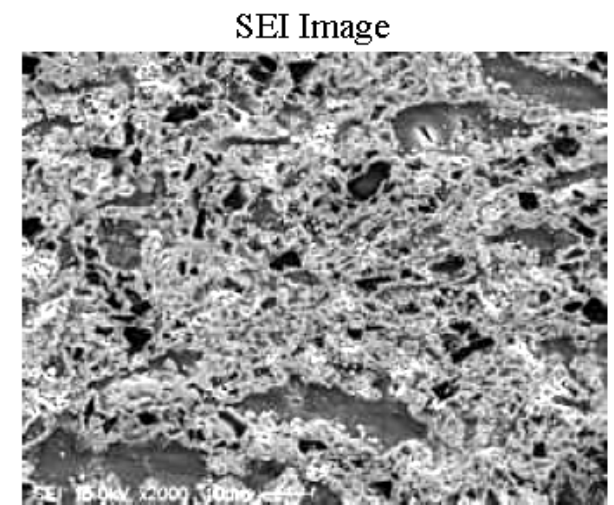

$\mathrm{Mg}-\mathrm{K} \alpha$ image

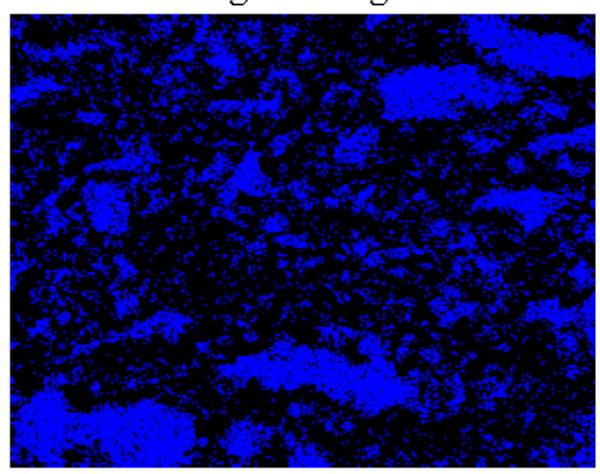

$\mathrm{C}-\mathrm{K} \alpha$ image

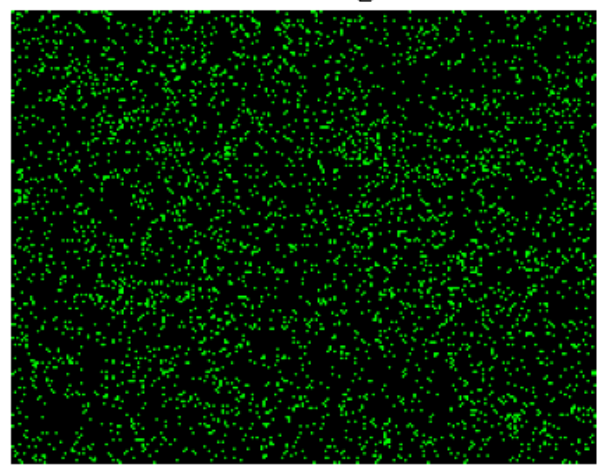

Ti-K $\alpha$ image

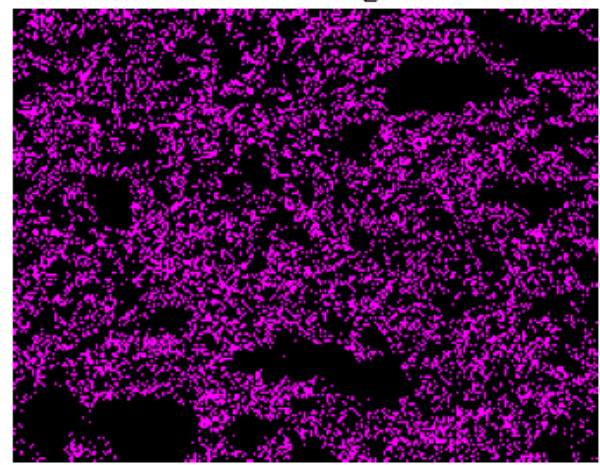

$\mathrm{B}-\mathrm{K} \alpha$ image

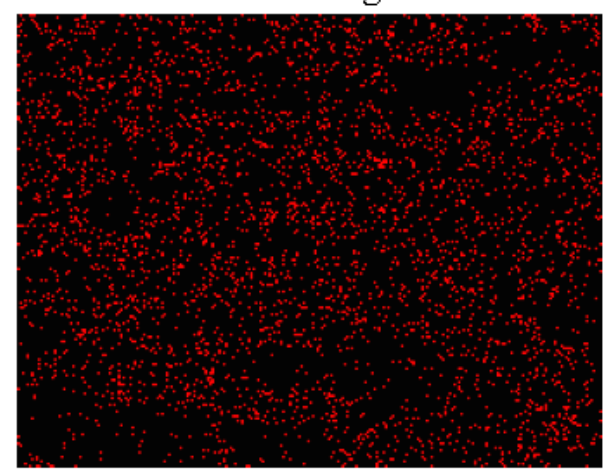

Al-K $\alpha$ image

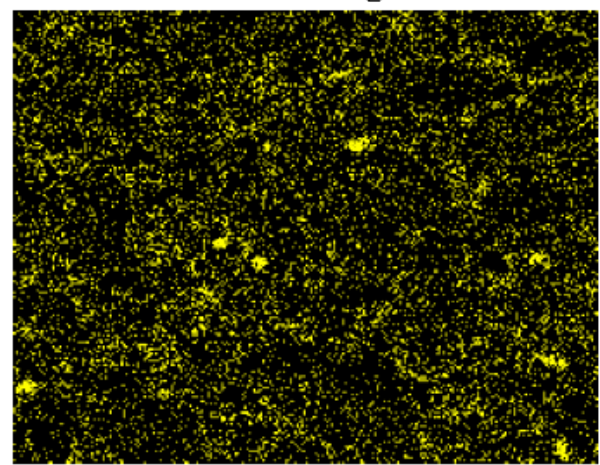

Figure 8. SEM microstructure and EDX elemental mapping of the R-Mg composites. 
From the above results, it can be concluded that the improvement in corrosion performance of R-Mg (with respect to AZ91D) relates to the dissolution of alpha magnesium from the R-Mg surface leaving titanium and boron networks which have nobler corrosion potential than that of alpha magnesium.

\section{CONCLUSIONS}

Reinforcement of AZ91D alloy with titanium carbides and borides improves the corrosion behaviour of the AZ91 D alloys. The Alfa magnesium was dissolved from the upper layer of $\mathrm{R}-\mathrm{Mg}$ surface due to interaction with the corrosive solution leaving the reinforced particles which have better corrosion properties. EN technique was successfully used to compare between AZ91D and the reinforced alloy. EN results indicated that corrosion behaviour of the reinforced alloy is improved with immersion time. Moreover, calculation $f_{\mathrm{n}}$ and $\mathrm{q}$ indicate that the AZ91D alloy is more susceptible to pitting corrosion than $\mathrm{R}-\mathrm{Mg}$ sample when immersed in dilute Harrison solution.

\section{References}

[1] Ghali E., Corrosion Resistance of Aluminum and magnesium Alloys. (2010), New York, USA: John Wiley \& Sons, Inc. 321.

[2] Ghali E., Magnesium and magnesium alloys, in Uhlig's Corrosion Handbook. (2000), John Wiley \& Sons: New York. p. 793.

[3] Heming Wang R.A., Mohamed Gobara, Corrosion Science 52(8) (2010) 2565-2570.

[4] G. Song, A. Atrens, Advanced Engineering Materials 5(12) (2003) 837-844.

[5] Almajid E.-S.S.a.A.A., International Journal of Electrochemical Science 6 (2011) 2131-2148.

[6] Yuan Guangyin S.Y., Ding Wenjiang, Scripta Materialia 43(11) (2000) 1009-1013.

[7] Zhou W., Aung Naing Naing, Sun Yangshan, Corrosion Science 51(2) (2009) 403-408.

[8] Byeong Ho Kim S.W.L., Yong Ho Park Ik Min Park, Journal of Alloys and Compounds 493(1-2) (2010) 502-506.

[9] Le Thu Q., G.P. Bierwagen S. Touzain, Progress in Organic Coatings 42(3-4) (2001) 179-187.

[10] Gui F., C.S. Brossia, Corrosion monitoring under coatings, in Techniques for corrosion monitoring, L. Yang, Editor. (2008 ), Woodhead Publishing Limited: Cambridge England.

[11] Martin Jönsson, D.P.a.C.L., Corrosion Science 50 (2008) 1406-1413.

[12] Zhiming Shi M.L., Andrej Atrens, Corrosion Science 52(2) (2010) 579-588.

[13] Tan, Y., S. Bailey, and B. Kinsella, Corrosion Science 38(10) (1996) 1681-1695.

[14] Ashassi-Sorkhabi H., D. Seifzadeh, Journal of applied electrochemistry 38(11) (2008) 1545-1552. 
[15] Ramezanzadeh B., et al., Applied Surface Science 289(0) (2014) 129-140.

[16] Cottis R.A., et al., Electrochimica Acta 46(24-25) (2001) 3665-3674.

[17] Chen A.-n., et al., Transactions of Nonferrous Metals Society of China 22(1) (2012) 228-240.

[18] Song G., The corrosion and protection of magnesium alloys. (2006), Beijing: Chemical Industry Press of China.

[19] A. Pardo, M.C.M., A.E. Coy, R. Arrabal, F. Viejo, E. Matykina, Corrosion Science 50(3) (2008) 823-834. 